\title{
Development of the personnel controlling model of oil organizations
}

\author{
Zemfira Gareeva, Gulnara Nizamova, Larisa Avdeeva, Irina Soloveva, and Dilara Musina
}

State Petroleum Technical University, Kosmonavtov str., 1, 450062 Ufa, Russia

\begin{abstract}
The purpose of the work is to develop proposals aimed at improving the personnel controlling model of oil organizations as a tool for managing the processes of personnel turnover. The experience of applying the system of personnel controlling in foreign countries has proven to be an effective system, providing the management with the relevant information base for timely tracking of changes in the indicators of personnel management and productivity indicators. There is theoretically confirmed interrelation between personnel turnover indicators and labor productivity that predetermines the necessity of monitoring of the given indicator in the system of personnel controlling. Meanwhile, the turnover rate itself is influenced by different internal and external factors. The suggested directions of improving the personnel controlling model consist in inclusion of the additional module, which provides the analysis of the statistical reporting; suggested system of the quantitative evaluation of the production personnel quality indicators; analytical procedure of revealing the reasons of the key personnel turnover by means of introduction of the block structure of the turnover factors evaluation of this personnel category, revealed by method of expert evaluation of the oil organization workers, which allows ranking those factors and timely develop the means of its solution. Theoretical and methodological basis of the research are the actual concepts of personnel management and personnel controlling systems study and development. Methods of expert evaluation, mathematical and statistical methods, correlation and regression analysis were used to carry out the task of estimation of the proposed recommendations.
\end{abstract}

\section{Introduction}

The relevance of the development of personnel controlling in the personnel management system is due to the following theoretical and practical reasons: the most important element of management is personnel and its competence; environment of increasing information flows and opportunities for multivariate decisions complicates the decision-making process for management, in this connection, there is a growing need for an information and methodological support tool, one of which is a high-quality personnel management system. Among the effective methods of personnel management, controlling is of significant importance.

Indeed, personnel controlling has become the most relevant in the era of transition to the information society, when the feedback and the role of personnel in the management system 
becomes relevant.

The use of personnel controlling in modern enterprises is often the key to a successful and timely response to the ongoing changes in internal and external factors.

As a result, modern qualitative personnel controlling allows linking typical parameters with linear substructures of the enterprise, and, according to V. Knaup, "to delimit powers of management system elements, tying responsibility to necessary estimating parameters" [1].

The subject of the study is the process of development and improvement of the personnel controlling model in the personnel management system of the oil organization in order to increase labor productivity.

The object of the study is the personnel management system of the oil organization.

\section{Materials and methods}

As the literature analysis and review of management systems of Russian organizations shows, the disadvantages of the Russian system of personnel controlling is a structural disunity in management; in operational time, all elements of the system are subordinated to different positions, due to which there is a "conservation" of deficiencies in the work of structures. The necessity of modifying the management technologies in our country is caused by the state of the personnel management system. German economist D. Hahn [2] actualizes the information function of controlling through support of decision-making of personnel management by means of control and centralization of information flows, due to which the practice-oriented role of personnel controlling becomes actual. The analysis of controlling concepts showed that in $80-90$ s the prevailing idea of personnel controlling function among European scientific community was the idea of controlling coordination of organization subsystems. Another direction of economic thought expressed, for instance, in the works of P. Horvath, M. Weber [3, 4] consider the organizational basis of personnel management. M. Weber offers the following representation of the structure of personnel controlling: the upper level of planning includes the initial phase, consisting of the formulation of plans and the implementation phase, leading long-term plans to mediumterm ones and operational goals. Integration of information flows in the organization becomes a determinant of personnel controlling efficiency.

The system of controlling includes a coordinated area of management, the essence of which consists of process and methodology: methodology includes principles, objectives, functions, methods, techniques and practices, while the process is a scheme of the produced process. The technique of controlling is carried out through a network of internal and external relations, consisting of computer and organizational structure.

Nowadays, the implementation of personnel controlling is carried out through a variety of models. Many European and domestic scientists analyzed the theoretical and methodological foundations of personnel controlling and researched the models of personnel controlling: D. Hahn, P. Horvath, A. Karminsky, N. Olenev, N. Primak, S. Falco, A. Kibanov, J. Weber [2, 3, 4, 5]. Practical aspects and strategies of effective management of the oil organization personnel were considered by I. Burenina, M. Gayfullina, S. Sayfullina, D. Musina in works [7, 8, 9].

Based on the analysis of current foreign and domestic models of personnel controlling, we proposed the directions of developing the system of personnel controlling in the organizations of the oil industry. 


\section{Results}

Analysis of theoretical materials allowed us to formulate the following interpretation of personnel controlling in oil organizations: "personnel controlling is a system of information-analytical and methodological support of management decision-making in the personnel management system to improve the efficiency of oil organizations."

Having considered the essence, principles, regularities of functioning of personnel controlling, having analyzed various methods and approaches of development of this issue presented in works [1-9], the improved personnel controlling model was developed based on the ideas and methods of D. Hahn, A. Karminsky, N. Olenev, who considered personnel controlling as the tool of management of turnover processes in the organization (figure 1).

In case of oil organizations, the improved personnel controlling model is implemented by entrusting the specialists of personnel management service to work out normativemethodical documents and regulations, which allows avoiding the creation of additional structures and introduction of high costs, but at the same time allows effectively building up information and communication flows both with the personnel of oil companies and with the managing part of the organization.

Accordingly, the introduction of an improved personnel controlling model allows reconsidering the range of priority tasks of the personnel management service of oil organizations and pointing an emphasis on the following:

- Timely provision of the oil organization with the necessary labor resources of certain qualification and competence;

- To develop and implement training and retraining programs for the personnel of the oil organization based on the results of the quantitative assessment of the qualitative characteristics of the personnel;

- To develop measures aimed at increasing productivity and reducing the turnover of key personnel based on the results of the identified factor assessments;

Improved personnel controlling model should be a mechanism for the organization to achieve objective indicators of personnel turnover and productivity.

To calculate the structural performance parameters of the improved personnel controlling model, we recommend using the following:

- Parameters of quantitative assessment of qualitative characteristic of personnel individual competitiveness in the aspect of staffing the organization with qualified personnel;

- Ranking of job satisfaction factors in the organization by the degree of influence of these factors on the formation of personnel turnover; 


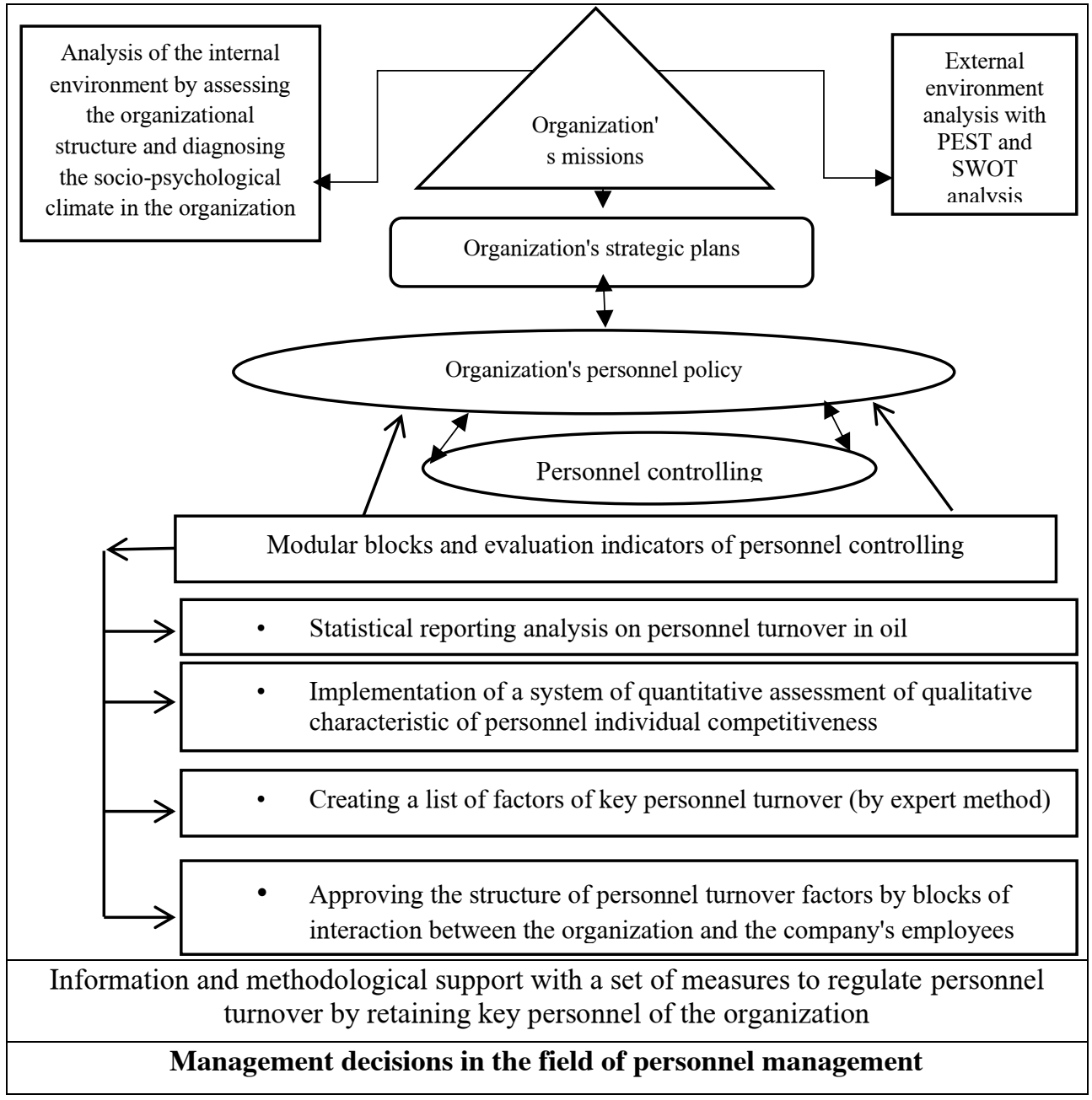

Fig. 1. Mechanism of implementation of the organizational and economic personnel controlling model

The proposed personnel controlling model of oil organizations assumes the inclusion of evaluation indicator module into the personnel controlling system, providing:

- Statistical reporting analysis;

- Implementation of the proposed system of quantitative assessment of personnel qualitative indicators (Table 2);

- analytical procedure of revealing the reasons of the key personnel turnover by means of introduction of the block structure of the turnover factors evaluation of this personnel category, revealed by method of expert evaluation of the oil organization workers, which allows ranking those factors and timely develop the means of its solution.

The works of various theorists and practitioners are devoted to the issues of personnel turnover $[10,11,12]$. For example, Deloitte in 2019-2020 conducted research on the causes of decreased labor productivity when reducing personnel turnover in the aspect of personnel management in the oil and gas industry and identified weaknesses in the organization of personnel controlling. Having analyzed the results of the study of the causes of reduced productivity in conditions of reduced personnel turnover in the aspect of personnel management in the oil and gas industry, among the main reasons, the lack of 
candidates with the necessary skills and the difficulty of retaining key personnel were identified.

In order to select the analyzed factors, we considered the works [11, 12]. The works considered the influence of such factors as job satisfaction, susceptibility to stress, commitment to company goals, risk levels, relationships with colleagues and many others.

The works consider aspects of the implementation of the proposed organizational and economic personnel controlling model, which provides for the introduction of the system of quantitative assessment of individual qualitative characteristics of the personnel into the personnel controlling service, based on which, at one of the refineries, a key production personnel of the organization was identified, being a part of the vertically integrated oil and gas company, in order to improve labor productivity, reduce personnel turnover, improve the goodwill and search for internal resources to improve personnel competitiveness.

Table 1. Author's scale of individual assessment of personnel competencies

\begin{tabular}{|c|c|c|c|}
\hline $\begin{array}{c}\text { Criterion } \\
\text { No. }\end{array}$ & $\begin{array}{c}\text { Employee evaluation } \\
\text { criteria }\end{array}$ & Feature & $\begin{array}{c}\text { Feature } \\
\text { score }\end{array}$ \\
\hline \multirow[t]{6}{*}{1} & \multirow[t]{6}{*}{$\boldsymbol{O}-$ Education level } & Secondary education & 1 \\
\hline & & Higher incomplete education & 2 \\
\hline & & Higher education & 3 \\
\hline & & Two university degrees & 4 \\
\hline & & MBA & 5 \\
\hline & & Candidate of Sciences & 6 \\
\hline \multirow[t]{5}{*}{2} & \multirow{5}{*}{$\begin{array}{l}\boldsymbol{S} \text { - Professional } \\
\text { experience in this } \\
\text { position }\end{array}$} & Less than a year & 1 \\
\hline & & $1-3$ & 2 \\
\hline & & $3-5$ & 3 \\
\hline & & $5-10$ & 4 \\
\hline & & Over 10 years & 5 \\
\hline \multirow[t]{3}{*}{3} & \multirow{3}{*}{$\begin{array}{l}\boldsymbol{R} \text { - Assessment of } \\
\text { the employee's } \\
\text { improvement activity }\end{array}$} & Paper publication & 1 \\
\hline & & Improvement suggestion & 1 \\
\hline & & Inventive activity & 1 \\
\hline \multicolumn{4}{|c|}{ Maximum score for the sum of $\boldsymbol{O}, \boldsymbol{S}, \boldsymbol{R}$ indicators - 14 points } \\
\hline 4 & \multirow{5}{*}{$\begin{array}{l}\boldsymbol{l}_{\mathbf{1}}-\text { Personality and } \\
\text { business profile }\end{array}$} & Ability to analytical thinking & \multirow{6}{*}{$\begin{array}{l}\text { Scores } \\
\text { range } \\
\text { from } 1 \\
-4, \\
\text { where: } \\
1 \text { point }\end{array}$} \\
\hline 5 & & Responsibility & \\
\hline 6 & & Working ability & \\
\hline 7 & & Initiative & \\
\hline 8 & & Sociability & \\
\hline & Maximum sco & for criterion $\boldsymbol{l}_{\mathbf{1}}-20$ points & \\
\hline 9 & \multirow{5}{*}{$\begin{array}{l}\boldsymbol{k}_{2}-\text { Complexity of } \\
\text { the work performed }\end{array}$} & Type of work & \multirow{12}{*}{$\begin{array}{l}\text { - low } \\
\text { level, } \\
2 \text { points } \\
- \\
\text { average } \\
\text { level, } \\
3 \text { points } \\
\text { - above } \\
\text { average } \\
\text { level, } \\
4 \text { points } \\
\text { - high } \\
\text { level }\end{array}$} \\
\hline 10 & & Independence level of the work performed & \\
\hline 11 & & Variety level of work & \\
\hline 12 & & Existence of additional responsibilities & \\
\hline 13 & & Degree of managerial responsibilities & \\
\hline \multicolumn{3}{|c|}{ Maximum score for criterion $\boldsymbol{k}_{2}-20$ points } & \\
\hline 14 & \multirow{6}{*}{$\begin{array}{l}\boldsymbol{l}_{2}-\text { Employee } \\
\text { performance }\end{array}$} & Scheduled work in quantitative assessment & \\
\hline 15 & & Unscheduled work in quantitative assessment & \\
\hline 16 & & Due dates of scheduled work & \\
\hline 17 & & Scheduled work in qualitative assessment & \\
\hline 18 & & Unscheduled work in qualitative assessment & \\
\hline 19 & & Due dates of unscheduled work & \\
\hline
\end{tabular}

The analysis of refinery reporting data for 2014 - 2019 showed that personnel turnover decreased by $0.3 \%$ below the level of 2018 , but at the same time labor productivity decreased (Table 3 ). 
Table 2. Refinery personnel turnover rates

\begin{tabular}{|l|l|l|l|l|l|l|}
\hline Rates & $\mathbf{2 0 1 4}$ & $\mathbf{2 0 1 5}$ & $\mathbf{2 0 1 6}$ & $\mathbf{2 0 1 7}$ & $\mathbf{2 0 1 8}$ & $\mathbf{2 0 1 9}$ \\
\hline Key personnel turnover, \% & 9.3 & 9 & 8.6 & 8.2 & 7.5 & 7.2 \\
\hline Labor productivity, million rubles/person & 9.5 & 13.4 & 13 & 15.4 & 14 & 13.5 \\
\hline
\end{tabular}

Conducted $\mathrm{ABC}$ analysis of personnel ranking by competence factor showed that $20 \%$ of the total number of employees are key personnel of the organization, which means that the problem of relevance of key personnel retention is relevant, as it is currently a significant criterion in the overall structure of personnel turnover (Table 4).

Table 3. ABC analysis of the personnel competitiveness of the refinery under study

\begin{tabular}{|c|c|c|c|c|}
\hline & High performance & $\begin{array}{c}(7 \%) \text { Value-based } \\
\text { personnel }\end{array}$ & $\begin{array}{c}(7 \%) \\
\text { Key personnel }\end{array}$ & $\begin{array}{c}(5 \%) \\
\text { Key personnel }\end{array}$ \\
\hline & Average & $\begin{array}{c}(8.5 \%) \\
\text { Passive Performer }\end{array}$ & $\begin{array}{c}(12 \%) \text { Value-based } \\
\text { personnel }\end{array}$ & $\begin{array}{c}(8 \%) \\
\text { Key personnel }\end{array}$ \\
\hline & $\begin{array}{c}(4 \%) \\
\text { performance }\end{array}$ & $\begin{array}{c}(39 \%) \\
\text { Passive Performer }\end{array}$ & $\begin{array}{c}(8.5 \%) \text { Value- } \\
\text { based personnel }\end{array}$ \\
\hline & $\begin{array}{c}\text { Below } \\
\text { expectations }\end{array}$ & Meets expectations & $\begin{array}{c}\text { Above } \\
\text { expectations }\end{array}$ \\
\hline
\end{tabular}

Block implementation to identify the factors, the causes of personnel turnover by expert assessment of employees of the oil organization allowed ranking these causes by their influence on the factor of personnel turnover formation at the refinery under study. The results of the study are presented in the final report (graphical interpretation shown in Figure 2) and the final table of values of the identified factors of personnel turnover, presented in Table 5.

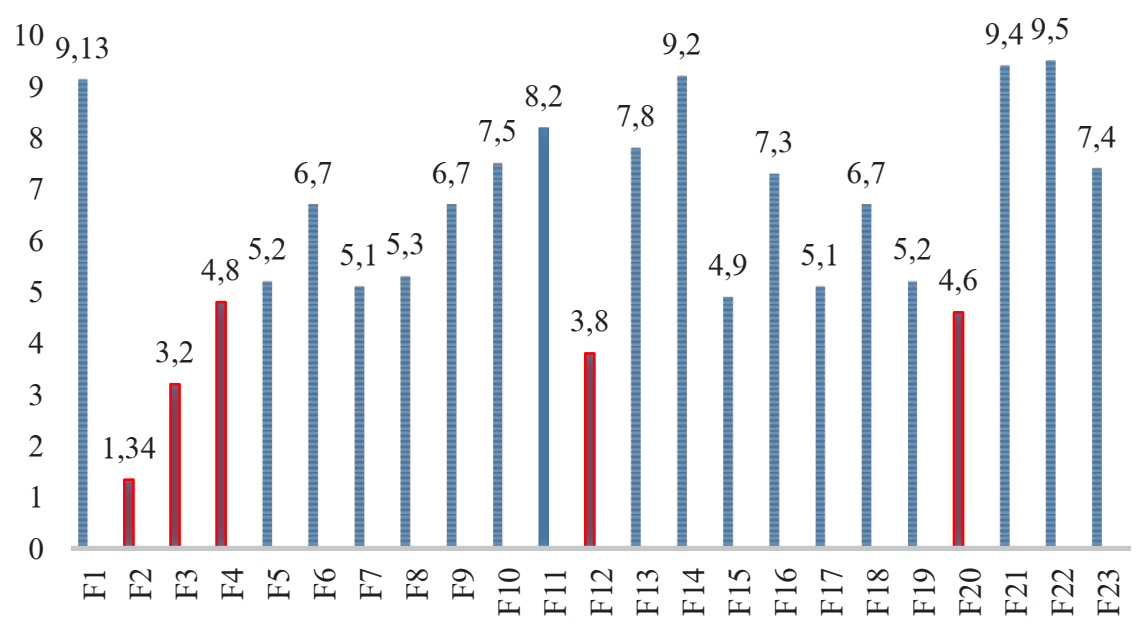

Fig. 2. Graphical interpretation of indicators of the total impact of the identified factors on the factor of personnel turnover formation

Table 4. Significance of the identified factors of personnel turnover

\begin{tabular}{|l|l|c|l|}
\hline No. & \multicolumn{1}{|c|}{ Factors } & Value & \% \\
\hline 1 & Overall job satisfaction & 0.86 & 0.99514 \\
\hline 2 & Material remuneration satisfaction & 8.66 & 10.02083 \\
\hline 3 & Objectivity of remuneration and incentives & 6.4 & 7.405693 \\
\hline 4 & Satisfaction with material incentives & 5.2 & 6.017126
\end{tabular}


Table 4. Continued

\begin{tabular}{|l|l|l|l|}
\hline 5 & Labor organization & 4.8 & 5.55427 \\
\hline 6 & Standardization of the working day & 3.3 & 3.818561 \\
\hline 7 & Working mode & 4.9 & 5.669984 \\
\hline 8 & Working conditions & 4.7 & 5.438556 \\
\hline 9 & Regulations of work process & 3.3 & 3.818561 \\
\hline 10 & State of work discipline & 2.5 & 2.892849 \\
\hline 11 & Distribution of workload among employees & 2.7 & 3.124277 \\
\hline 12 & Socio-psychological atmosphere & 6.2 & 5.35804 \\
\hline 13 & Compliance of management requirements with & 2.2 & \\
& functional responsibilities of employees & & 2.545707 \\
\hline 14 & Material and technical support of the work process & 0.8 & 0.925712 \\
\hline 15 & Opportunity to implement their creative potential & 5.1 & 5.901412 \\
\hline 16 & Job autonomy & 2.7 & 3.124277 \\
\hline 17 & Position held & 4.9 & 5.669984 \\
\hline 18 & Job content & 3.3 & 3.818561 \\
\hline 19 & Career advancement opportunities & 5.4 & 5.55427 \\
\hline 20 & Professional training and retraining & 0.6 & 0.248554 \\
\hline 21 & Management competence & 0.5 & 0.57857 \\
\hline 22 & Management demandingness & 2.6 & 3.008563 \\
\hline 23 & Feedback mechanism & \\
\hline
\end{tabular}

Reducing the key personnel turnover and ranking the identified factors of the turnover of this share of personnel is a significant criterion for reducing the overall personnel turnover and increasing productivity.

The conducted regression analysis showed that personnel turnover has a significant reserve for improving not only the system of labor force, but also for improving the overall organization performance. The review of economic and mathematical methods of study of turnover problems was considered by A. Kadyrova in work [13]. To assess the relationship between the indicator of turnover and labor productivity, the method of S. Mamedova, outlined in work [14], was used. The correlation analysis between the turnover rate of the refinery personnel and labor productivity revealed a high inverse relationship (-0.720). In the course of further calculations it was determined that the reduction of personnel turnover at the refinery under study by $1 \%$ increases labor productivity by 2.143 million rubles.

As a result of the calculations we can conclude that the proposed improved personnel controlling model, which is based on a quantitative assessment of the qualitative results of the individual competitiveness, and allows finding the impact factors of the causes of key personnel withdrawal, according to the regression analysis, has a significant reserve of increasing labor productivity. As a result, it should be concluded that the proposed improved personnel controlling model is an effective tool for improving the personnel management system, and the proposed methods are an effective tool for obtaining information for making further managerial decisions.

\section{Conclusions}

The following results were obtained as a result of the study:

1. The indicators for assessing the effectiveness of personnel controlling based on the use of a scale of quantitative assessment of qualitative indicators of individual competence of employees of an oil organization were offered, including an assessment of the professional and qualification level of the employee, personal and business characteristics, the complexity of the work performed, work results and the final indicator of assessment of professional and qualification level of personnel. 
2. The improvement of personnel controlling model based on the methods of D. Hahn, A.M. Karminsky, N.K. Olenev by introduction of quantitative assessment of individual qualitative indicators of personnel characteristics into personnel controlling service, which will increase the efficiency of organization productivity and personnel turnover management.

3. The personnel controlling model of oil organizations has been improved by introducing a block into the controlling structure to identify the factors, the causes of personnel turnover based on the factors identified by expert assessment of the employees of the oil organization, allowing to rank these causes and to develop timely measures to solve them.

4. Taking into account the proposed recommendations, an analysis of key personnel turnover factors at an oil refinery, being part of one of the vertically integrated companies, was carried out. The results of the correlation and regression analysis showed that the reduction of key personnel turnover at the refinery by $1 \%$ makes it possible to increase labor productivity by $2.143 \mathrm{mln}$.

\section{References}

1. V. Knaup, Controlling as a system of improving the management efficiency, 119 (1998)

2. D. Hahn, Controllingkonzepte. Planung und Kontrolle; Planungs- und Kontrollsysteme; Planungs- und Kontrollrechnung, 439 (2014)

3. P. Horvath, Introduction to controlling, 121 (2006)

4. M. Weber, General Sociology. Chrestomathy, 783 (2016)

5. A.M. Karminsky, Controlling in business - Methodological and practical foundations of creating controlling in organizations, 256 (Finance and Statistics, 2008)

6. N.V. Baranova, A.Y. Vklad, A.Y. Kibanov, Human progress, 4(9) (2018) http://progresshuman.com

7. M.M. Gayfullina, G.Z. Nizamova, IOP Conference Series: Earth and Environmental Science, 459(6), 062041 (2020)

8. S. A. Wisconte, D.R. Musina, M.V. Gerasimova, A.V. Yangirov, S.I. Nasyrova, Company Efficiency Assessment Using Key Indicator System. Advances in Economics, Business and Management Research: International Scientific Conference "Far East Con" (ISCFEC 2020), 128, 3044 (2020)

9. M.M. Gayfullina, I.V. Burenina, S.F. Sayfullina European Proceedings of Social and Behavioural Sciences EpSBS, 790

10. L. Porter, R. Steers, Psychological Bulletin, 80(2), 151 (1973)

11. A.B. Sunal, O. Sunal, F. Yasin, Social Indicators Research, 102, 265 (2011)

12. R. Iverson, S. Kuruvilla, Journal of Management, 15, 15 (1994)

13. A.R. Kadyrova, Management issues, 3 (2015)

14. S.T. Mammadova, Oil, Gas and Business, 12, 28 (2017)

15. K.S. Gushchenskaya, Z.A. Gareeva, The use of mathematical and statistical modeling in the personnel management system, Collection of scientific papers of the IV AllRussian Scientific and Practical Conference "Actual issues of economy and management in oil and gas business.", 26 (2020) 